УДК 621.396 .69

\title{
ДОБРОТНОСТЬ ПЕРЕСТРАИВАЕМЫХ МИКРОПОЛОСКОВЫХ РЕЗОНАТОРОВ
}

\author{
СЕРГИЕНКО П. Ю., КАЗМИРЕНКО В. А., ЧЕРНОВ А. С., ПРОКОПЕНКО Ю. В. \\ Национальный технический университет Украины \\ «Киевский политехнический институт», \\ Украина, Киев, 03056, пр-т Победы 37
}

\begin{abstract}
Аннотация. Статья посвящена изучению добротности микромеханически перестраиваемых резонаторов и ее изменению при перестройке резонансной частоты. Для рассмотренных в работе резонаторов собственная добротность увеличивается на 10\% при перестройке за счет уменьшения диэлектрических потерь в объеме подложки и омических потерь в металле электродов. Потери обоих механизмов аддитивны когда общий уровень потерь в линии намного меньше полезного сигнала, поэтому для расчета значения потерь и перестройки резонансной частоты используется комплексная диэлектрическая проницаемость
\end{abstract}

Ключевые слова: микрополосковая линия; микромеханическая перестройка; эффективная диэлектрическая проницаемость; резонатор; потери электромагнитной энергии; добротность

\section{ВВЕДЕНИЕ}

Одним из базовых требований к устройствам радиоэлектроники и техники связи является возможность перестройки рабочей частоты. В последние годы диапазон перестройки рабочей частоты существенно расширился благодаря применению современных сосредоточенных компонентов. Одной из проблем перестраиваемых пассивных микрополосковых компонентов (фильтры, фазовращатели, и т.п.) является ухудшение собственной добротности при внедрении в их структуру элементов управления. Варакторы [1, 2], $p-i-n$ диоды [3] и другие сосредоточенные компоненты вносят потери, обусловленные внутренними процессами в них, что отрицательно сказывается на собственной добротности резонаторов.

В то же время, перестройка за счет механических перемещений частей системы с использованием микроелектромеханических систем (MEMC) $[4,5]$ или пьезоэлектрических актюа- торов позволяет не только сохранить полосу пропускания резонатора, но и не ухудшает его собственную добротность. Механически перемещаемые перестраиваемые части изменяют электрическую длину резонатора, но при этом не вносят дополнительных потерь, в отличие от сосредоточенных компонентов. При этом механическая перестройка обеспечивает высокую чувствительность резонансной частоты. Например, смещение управляющего электрода на десятки микрометров приводит к значительным изменениям свойств резонатора [6].

Структура предложенной микрополосковой линии с микромеханической перестройкой показана на рис. 1 , где $h_{1}$ - высота подложки, $w$ - ширина сигнального электрода, $\varepsilon_{1}$ - диэлектрическая проницаемость подложки, $\varepsilon_{2}-$ диэлектрическая проницаемость управляемой неоднородности (воздух, тонкая пленка, пьезоэлектрик, и т.п.), $h_{2}$ - высота управляемой неоднородности. 